\title{
Hyperglobulinaemic Renal Tubular Acidosis: A Report of Nine Cases
}

\author{
ALASTAIR M. S. MASON,* M.B., M.R.C.P. ; PETER L. GOLDING, † M.B., M.R.C.P.
}

\begin{abstract}
Summary: Of nine women with hyperglobulinaemic renal tubular acidosis four presented with acidosis and five had the "incomplete" form of the disorder. Seven patients had nephrogenic diabetes insipidus, but none had the Fanconi syndrome. Investigation showed abnormal immunoglobulins and autoantibodies in all nine patients. Diseases coexisting with renal tubular acidosis were Sjögren's syndrome, hyperglobulinaemic purpura, autoimmune liver and thyroid disease, diffuse pulmonary fibrosis, and a peripheral neuropathy. It is suggested that this type of renal tubular acidosis might be due to an autoimmune process.
\end{abstract}

\section{Introduction}

Renal tubular acidosis may be defined as an inability of the renal tubule to acidify urine normally which is out of proportion to any reduction in the glomerular filtration rate. Huth et al. (1960) divided patients with renal tubular acidosis into two main groups, the first being mainly males seen during the first year of life. The second group presented after the first year and consisted mainly of females. In this group the disorder has been associated with multiple myeloma, chronic pyelonephritis, Wilson's disease, and hypokalaemia (Milne, 1963).

There have recently been reports of the concurrence of renal tubular acidosis in adults with non-organ-specific autoimmune diseases such as Sjögren's syndrome (Shearn and Tu, 1965; Morris and Fudenberg, 1967), hyperglobulinaemic purpura (Greenspan, 1949; Cohen and Way, 1962), and active chronic hepatitis (Read et al., 1963; Seedat and Raine, 1965). Cases of renal tubular acidosis without clinical evidence of a coexisting autoimmune disease have been shown to have hyperglobulinaemia and non-organ-specific antibodies (Wilson et al., 1967; Talal et al., 1968). It has been suggested that the acidification defect in these cases is due to an autoimmune process (Talal et al., 1968), and the syndrome has been called hyperglobulinaemic renal tubular acidosis (McCurdy et al., 1967).

\section{Patients and Methods}

Nine patients under the care of physicians at The London Hospital and in the Wessex Region were studied. Some details of two (Cases 1 and 4) have been previously reported (Foss et al., 1956; Smith et al., 1967). Two patients initially presented with symptoms attributable to renal tubular acidosis. The remainder were diagnosed either because renal tubular acidosis developed during the course of another disease or the "incomplete" form was detected while screening a group of patients with hyperglobulinaemia (Table I).

It was considered unnecessary to perform an ammonium chloride test in those patients with an overt acidosis (plasma bicarbonate below $20 \mathrm{mEq} / \mathrm{l}$.) while passing urine with a $\mathrm{pH}$ greater than 6 . In the other patients an ammonium chloride loading test was performed with the method described by Wrong and Davies (1959). Renal concentrating ability was tested by measuring the maximum urine S.G. obtained after the administration of 5 units of pitressin tannate in oil. $A$

*Senior House-physician, Southampton General Hospital.

tSenior Registrar in General Medicine, The London Hospital. maximum S.G. of less than 1020 was considered to be abnormal. Urinary amino-acids were detected by two-dimensional paper chromatography.

The patients were investigated for evidence of other disorders associated with hyperglobulinaemia.

TABLE I.-Diseases Occurring with Hyperglobulinaemic Renal Tubular Acidosis in Nine Patients

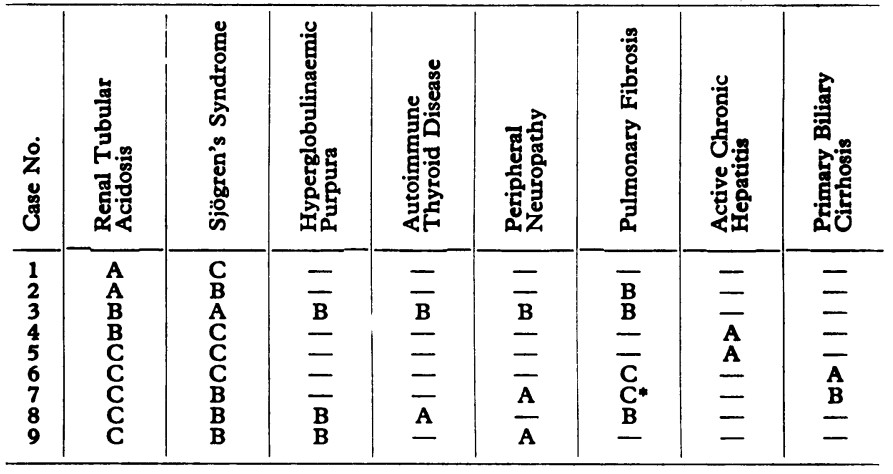

$A=$ Initial diagnosis. $B=$ Diagnosis made before this investigation. $C=$ Diagnosis made during this investigation. *Transfer defect only.

\section{Results}

\section{Renal Function}

Four of the patients had an overt acidosis and presented with muscular weakness (Cases 1 and 4), bone pain (Case 2), and vomiting and polyuria (Case 3 ). Biochemical investigation showed a hypokalaemic hyperchloraemic acidosis while passing urine with a $\mathrm{pH}$ greater than 6. All four had nephrogenic diabetes insipidus but none had the Fanconi syndrome. The creatinine clearance at the time of diagnosis ranged from 50 to 73 (average 62) $\mathrm{ml} . / \mathrm{min}$. Two patients had nephrocalcinosis, two hypocalcaemia, one osteomalacia, and one hypercalciuria (Table II).

The five patients with the "incomplete" form of the disorder were unable to acidify their urine below a $\mathrm{pH}$ of 5.7 during an ammonium chloride test. The maximal ammonium excretion was normal or high in all cases. One patient had hypokalaemia, and she and two others had nephrogenic diabetes insipidus. The creatinine clearance ranged from 51 to 89 (average 68 ) $\mathrm{ml} . / \mathrm{min}$. (Table III).

\section{Immunological Investigations}

An abnormality of the serum immunoglobulins was detected in all nine patients (Table IV). The IgG fraction was raised in eight, IgA in three, and IgM in two. In addition, one (Case 4) had a large amount of monomer IgM present in the serum.

The rheumatoid screen test was positive in eight patients, and two had positive sheep cell agglutination and F II tests. An antinuclear antibody was present in six, and smooth muscle antibody in three. Mitochondrial immunofluorescence was detected in two cases, and autoimmune complement fixation tests were also positive in two. Raised titres of thyroglobulin antibody were detected in four patients. The immunoconglutinin titre was measured in five being markedly raised in four. 
TABLE II.-Features Present at Diagnosis in Four Patients with an Overt Acidosis

\begin{tabular}{|c|c|c|c|c|c|c|}
\hline & & & Case 1 & Case 2 & Case 3 & Case 4 \\
\hline Age $\because, \quad \cdots \quad \cdots, \quad \because$ & & & 45 & 30 & 61 & 35 \\
\hline Creatinine clearance (ml./min.) & . & $\therefore$ & 66 & 73 & 60 & 50 \\
\hline Bicarbonate (mEq/l.) & .. & $\ldots$ & 17 & 18 & 9 & 12 \\
\hline Chloride (mEq/l.) & . & . & 117 & 118 & 110 & 114 \\
\hline Potassium (mEq/1.) & .. & . & $2 \cdot 6$ & $2 \cdot 5$ & $2 \cdot 6$ & $2 \cdot 7$ \\
\hline Calcium (mg. $/ 100 \mathrm{ml})$. & . & .. & $9 \cdot 7$ & $8 \cdot 8$ & $6 \cdot 0$ & $9 \cdot 8$ \\
\hline Urine $p \mathrm{H}$ & .. & . & $6 \cdot 4$ & $6 \cdot 8$ & $6 \cdot 4$ & $6 \cdot 8$ \\
\hline Nephrocalcinosis & .. & . & + & + & - & - \\
\hline Osteomalacia.. & . & . & - & + & - & - \\
\hline Hypercalciuria $\quad \ldots, \quad \ldots$ & . & .. & - & - & - & + \\
\hline Nephrogenic diabetes insipidus & . & . & + & + & + & + \\
\hline Aminoaciduria $\quad \ldots \quad \ldots$ & .. & . & - & - & - & - \\
\hline Phosphaturia.. & .. & . & - & + & - & - \\
\hline
\end{tabular}

TABLE III.-Features Present in Five Patients with the "Incomplete" Form of Renal Tubular Acidosis

\begin{tabular}{|c|c|c|c|c|c|}
\hline & Case 5 & Case 6 & Case 7 & Case 8 & Case 9 \\
\hline $\begin{array}{lllll}\text { Age } & . & . . & \ldots & \ldots\end{array}$ & 34 & 58 & 64 & 58 & 47 \\
\hline $\begin{array}{l}\text { Acid load test: } \\
\text { Minimum } p \mathrm{H} . \\
\text { Maximum T.A. }(\mu \mathrm{Eq} / \mathrm{min} .) \\
\text { Maximum ammonium }\end{array}$ & $20^{6 \cdot 0}$ & $\begin{array}{c}5 \cdot 8 \\
19\end{array}$ & $\begin{array}{c}5 \cdot 7 \\
18\end{array}$ & $\begin{array}{c}6 \cdot 4 \\
18\end{array}$ & $\begin{array}{l}6 \cdot 2 \\
8\end{array}$ \\
\hline $\begin{array}{l}(\mu \mathrm{Eq} / \mathrm{min} .) \\
\text { Creatinine clearance } \\
\text { Hypokalaemia }\end{array}$ & $\begin{array}{l}42 \\
51 \\
+\end{array}$ & $\begin{array}{r}131 \\
68 \\
-\end{array}$ & $\begin{array}{l}55 \\
63 \\
-\end{array}$ & $\begin{array}{l}59 \\
69 \\
-\end{array}$ & $\begin{array}{l}64 \\
89 \\
-\end{array}$ \\
\hline Nephrogenic diabetes insipidus.. & + & - & + & - & + \\
\hline
\end{tabular}

T.A. $=$ Titratable acidity.

\section{Associated Diseases}

All the cases of hyperglobulinaemic renal tubular acidosis in this series had a coexisting autoimmune disorder (Table I). All had keratoconjunctivitis sicca and xerostomia, and seven had a history of recurrent parotitis. None had evidence of rheumatoid arthritis. Three patients had recurrent attacks of hyperglobulinaemic purpura, but these ceased after steroid therapy. Four cases had autoimmune liver disease-Cases 4 and 5 showed clinical, biochemical, and immunological evidence of active chronic hepatitis, and in Cases 6 and 7 these criteria were diagnostic of primary biliary cirrhosis. The liver biopsy was compatible with the diagnosis in all four cases. Serum and urinary copper levels were normal in the two cases with primary biliary cirrhosis.

Three cases had a mixed sensory-motor neuropathy-in Cases 3 and 9 the defect was predominantly motor, but in Case 7 mainly sensory. The neurological symptoms improved after steroid therapy. There was evidence of diffuse pulmonary fibrosis in five cases. In Case 2 there was biopsy evidence of an alveolar lesion, but the presence of both autoantibodies and avian precipitins with a strong history of exposure to a pet bird made diagnosis difficult. Cases 3, 6, and 8 had clinical, radiological, and lung function evidence of pulmonary fibrosis. These criteria all improved after steroid therapy. Case 7 had a severely impaired transfer defect without other evidence of a lung lesion.

Autoimmune thyroid disease occurred in two patientsCase 3 presented with myxoedema and Case 8 had hyperthyroidism, and following thyroidectomy became rapidly myxoedemic. A biopsy specimen of the gland showed the changes of Hashimoto's thyroiditis.

\section{Discussion}

Hyperglobulinaemic renal tubular acidosis occurs predominantly in women. All our patients were female, and only two previously recorded cases of hyperglobulinaemic renal tubular acidosis were male (Greenspan, 1949; Bennett et al., 1968). The age at diagnosis in our patients ranged from 30 to 64, with an average of 48 . The range in the 34 cases of hyperglobulinaemic renal tubular acidosis in the literature was 16 to 76 years, and the onset was commonest in the fifth decade.

Renal tubular acidosis may present as an overt hyperchloraemic acidosis or in the incomplete form, which is found only when the renal tubules are stressed with an acid load (Wrong and Davies, 1959). Probably the two forms differ only in the degree of impairment of the total hydrogen ion excretion, as instances of incomplete renal tubular acidosis becoming overtly acidotic have been recorded (Wrong, 1965). Four of our patients presented with an acidosis, and five had the incomplete form of the syndrome, though none of the latter have been found to become overtly acidotic. Wrong and Davies (1959) postulated that the acidosis became overt when the excretion of ammonium ion was impaired, which occurred when generalized renal destruction caused a reduction in the glomerular filtration rate. The average rate of the group with an acidosis in our series was slightly less than that of the incomplete group, but there was considerable overlap. The creatinine clearance has been measured in 23 cases of hyperglobulinaemic renal tubular acidosis in the literature. In the 16 with an overt acidosis the range was from 21 to 110 (average 52) $\mathrm{ml} . / \mathrm{min}$., while in the seven cases with the incomplete form the creatinine clearance varied from 63 to 102 (average 78 ) $\mathrm{ml} . / \mathrm{min}$. There was considerable overlap between the groups, and though a reduction in glomerular filtration rate may play a part in the development of the acidosis, other factors are probably involved.

Morris (1969) showed that the disorder of function in renal tubular acidosis may be of two main types. In the first the proximal tubule is mainly implicated and the associated tubular defect is the Fanconi syndrome. The maximal tubular reabsorption of bicarbonate $\left(\mathrm{TmHCO}_{3}\right)$ is impaired, and the disorder is probably due to a defect in the rate of hydrogen ion excretion in the proximal tubule. The second type involves mainly the distal tubule, the associated defect is nephrogenic diabetes insipidus, and the $\mathrm{TmHCO}_{3}$ is normal. The acidosis is probably due to an inability to maintain the hydrogen ion gradient across the distal renal tubule. Seven of our patients have nephrogenic diabetes insipidus, and thus can be classified in the latter group. None had the Fanconi syndrome. Only two previously reported cases of hyperglobulinaemic renal tubular acidosis have had the Fan-

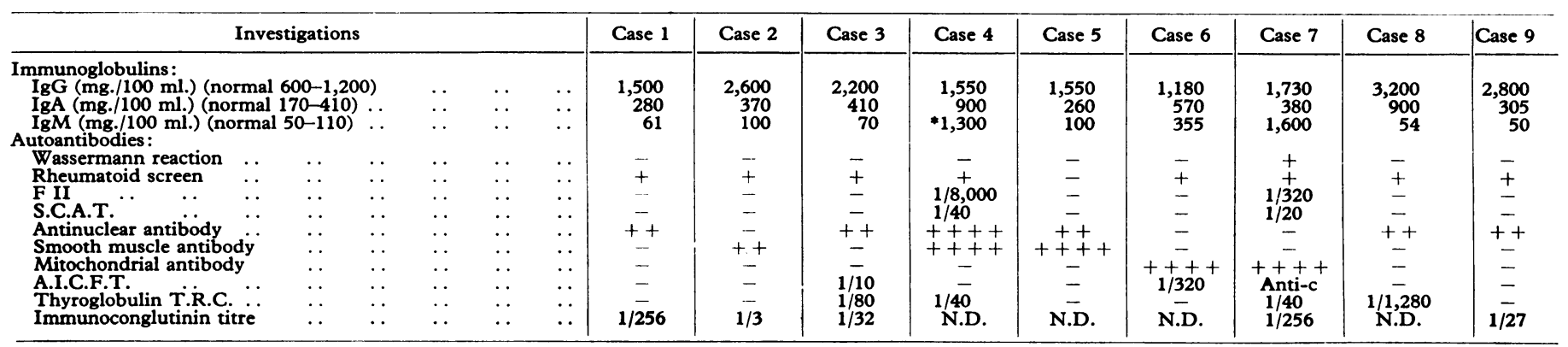

-Ultracentrifugation showed the $19 \mathrm{~s}$ component to be normal. A.I.C.F.T. $=$ Autoimmune complement fixation tests. Anti-c = Anti-complementary. S.C.A.T. = Sheep cell agglutination test. N.D. $=$ Test not done. 
coni syndrome (Shearn and Tu, 1965; Bennett et al., 1968), but 16 have had nephrogenic diabetes insipidus. Morris et al. (1968) measured the $\mathrm{TmHCO}_{3}$ in two women with Sjögren's syndrome and renal tubular acidosis. In one it was normal and she had nephrogenic diabetes insipidus, while the other had a greatly impaired $\mathrm{TmHCO}_{3}$ and the associated tubular defect was amino-aciduria. Though both types of disordered function may be found in patients with hyperglobulinaemic renal tubular acidosis the "distal tubule defect" occurs far more commonly.

Abnormalities of the serum immunoglobulins were present in all nine patients. The oommonest defect was an increase in the IgG fraction. Serum immunoglobulin components have been measured in 17 of the recorded cases of hyperglobulinaemic renal tubular acidosis (Shearn and $\mathrm{Tu}$, 1965; McCurdy et al., 1967; Morris and Fudenberg, 1967; Wilson, et al., 1967; Talal et al., 1968). The IgG fraction was raised in 16, IgA in 10, and IgM in six. In cases of renal tubular acidosis without an associated autoimmune disease the IgG fraction was raised in all five, $\operatorname{IgA}$ in three, and $\operatorname{IgM}$ in two (McCurdy et al., 1967; Morris and Fudenberg, 1967; Wilson et al., 1967; Talal et al., 1968).

All patients in our series had autoantibodies in the serum. Rheumatoid factor and an antinuclear antibody were commonest, but no specific pattern would seem to be diagnostic. Serological investigations have been recorded in 10 cases of hyperglobulinaemic renal tubular acidosis (McCurdy et al., 1967; Wilson et al., 1967; Talal et al., 1968). A positive rheumatoid factor was present in all these and an antinuclear antibody in five. In four there was no clinical evidence of another autoimmune disease. The nine cases in our series and 26 of the 34 previously reported have had at least one concurrent autoimmune disease. All our cases had the "sicca complex" form of Sjögren's syndrome. Individual reports of an association between renal tubular acidosis and Sjögren's syndrome (Shearn and Tu, 1965; Morris and Fudenberg, 1967) have been substantiated by two screening studies. Shearn and Tu (1968) found three cases with impaired acidification in a series of 10 unselected patients with Sjögren's syndrome. In a series of 12 patients, three having overt electrolyte abnormalities, Talal et al. (1968) found six with a defect of acidification, all having the "sicca complex" form of Sjögren's syndrome. Five of these six also had purpura, confirming reports of the concurrence of renal tubular acidosis with hyperglobulinaemic purpura (Greenspan, 1949; Pines and Mudge, 1951; Cohen and Way, 1962). Three patients in our series had a history of recurrent attacks of purpura, and in none was a coagulation defect or a cryoglobulin found.

Two of our cases had active chronic hepatitis, and this association has been reported previously (Morris and Fudenberg, 1967; Read et al., 1963; Seedat and Raine, 1965). The concurrence of renal tubular acidosis with primary biliary cirrhosis has been recorded only once (Leeson and Fourman, 1967), and the defect of renal acidification in this patient was thought to be caused by a raised level of serum copper. The serum and urinary copper levels in our two patients with primary biliary cirrhosis were normal, and this mechanism was not responsible for their renal tubular acidosis. Autoimmune thyroid disease was present in two of our patients and there are three previous reports of this association. In two patients hyperglobulinaemia was found (Clinicopathological Conference, 1968; Zisman et al., 1968) but in the third (Huth et al., 1959) the acidification defect was thought to be secondary to a transient hypercalcaemia.

Three of our cases had peripheral neuropathy, and this association has been recorded once (Kaltreider and Talal, 1969). An association between renal tubular acidosis and diffuse pulmonary fibrosis has not been recorded before. Four of our patients had clinical, radiological, and lung function evidence of pulmonary fibrosis, and one other had a reduced transfer factor. Eight of our patients had multiple disorders, and there are seven previously reported cases of renal tubular acidosis occurring with two or more autoimmune diseases (Tables I and V). Probably the diseases included in these two

TABLE V.-Summary from the Literature of Cases with Multiple

\begin{tabular}{|c|c|c|c|c|c|c|c|}
\hline 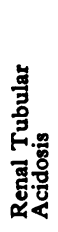 & 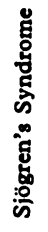 & 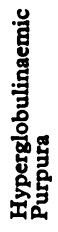 & 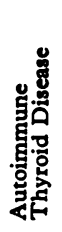 & 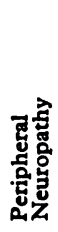 & 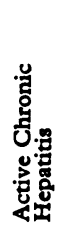 & 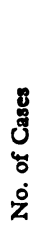 & Reference \\
\hline $\begin{array}{l}+ \\
+ \\
+\end{array}$ & $\begin{array}{l}+ \\
+ \\
+ \\
-\end{array}$ & $\begin{array}{l}+ \\
+ \\
+ \\
+\end{array}$ & $\begin{array}{l} \pm \\
- \\
\bar{t}\end{array}$ & $\begin{array}{l}\overline{+} \\
\pm \\
-\end{array}$ & $\overline{-}$ & $\begin{array}{l}1 \\
1 \\
3\end{array}$ & $\begin{array}{l}\text { Talal et al. (1968) } \\
\text { Kaltreider and Talal (1969) } \\
\text { Morris and Fudenberg (1967) } \\
\text { Talal et al. (1968) } \\
\text { Cohen and W Wy (1962) } \\
\text { Read et al. (1963) }\end{array}$ \\
\hline
\end{tabular}

tables might occur together. Some combinations occur with relative frequency, and it has been suggested that hyperglobulinaemic renal tubular acidosis, Sjögren's syndrome, and purpura constitute a clinical triad (Talal et al., 1968).

The pathogenesis of the acidification defect in these cases is not known, but probably it is due to an immunological disturbance. The presence of non-organ-specific autoantibodies and the concurrence of hyperglobulinaemic renal tubular acidosis with other autoimmune disorders suggest that autoimmune processes might be involved in the development of the renal lesion. Renal biopsies have shown tubular atrophy with an interstitial infiltration of lymphocytes and plasma cells, changes resembling those found in other organs involved in autoimmune diseases (Talal et al., 1968). Possibly the high levels of immunoglobulin might damage the renal tubules, but no correlation between immunoglobulin concentration and the development of a defect in acidification has been found (Morris and Fudenberg, 1967). Other diseases thought to be autoimmune were looked for in the patients in our series. All nine cases were shown to have a coexisting disorder, suggesting that the acidification defect may be part of a systemic disorder which can involve many organs.

The term "renal tubular acidosis" is applicable to a disorder of function and it is not a specific disease entity. Probably one of the causes in the adult, particularly in women, is an immunological disturbance characterized by hyperglobulinaemia and the presence of non-organ-specific autoantibodies. Further studies are required to determine the frequency with which renal tubular acidosis occurs in hyperglobulinaemic states, and the mechanisms involved in its pathogenesis.

We thank Dr. J. Bamforth, Dr. C. J. Earl, Dr. D. J. McGill, Dr. A. Stuart-Mason, and Dr. K. M. Robertson for permission to study patients under their care; and Dr. G. Franglen, Dr. P. J. Lachmann, and Mr. R. Lloyd for performing the immunological investigations. The work was supported by grants from the Medical Research Council (for A.M.S.M.) and The London Hospital Free Funds (for P.L.G.).

Requests for reprints should be sent to Dr. A. M. S. Mason, c/o Endocrine Department, The London Hospital, Whitechapel, London E.1.

\section{REFERENCES} Bennett, W. M.; Hempel, K. H., Berland, J. E., and Porter, G. A.
(1968). Archives of Intermal Medicine, 121, 81. Clinicopathological Conference (1968). New England fournal of Medi- 
Cohen, A., and Way, B. J. (1962). Australasian Annals of Medicine, 11, 189.

Foss, G. L., Perry, C. B., and Wood, F. J. (1956). Quarterly fournal Greef

Huth, E. J., Maycock, R. L., and Kerr, R. M. (1959). American fournal

Huth, E. J., Webster, G. D., and Elkington, J. R. (1960). American fournal of Medicine, $29,586$.

Kaltreider, H. B., and Talal, N. (1969). Annals of Internal Medicine, 70,751. Leeson, P. M., and Fourman, P. (1967). American fournal of Medicine,
43, 620.

McCurdy, D. K., Cornwell, G. G., and DePratti, V. J. (1967). Annals of Internal Medicine, 67, 110.

Milne, M. D. (1963). In Diseases of Kidney, ed. M. B. Strauss and L. G. Welt, p. 786. Boston, Little, Brown.

Morris, R. C. (1969). New England fournal of Medicine, 281, 1405.

Morris, R. C., and Fudenberg, H. H. (1967). Medicine, 46, 57.

Morris, R. C., Sebastian, A., Morris, E., and Ueki, I. (1968). fournal of Clinical Investigation, 47, 70a.
Pines, K. L., and Mudge, G. H. (1951). American fournal of Medicine, 11, 302.'

Read, A. E., Sherlock, S., and Harrison, C. V. (1963). Gut, 4, 378.

Seedat, Y. K., and Raine, E. R. (1965). South African Medical fournal, $39,595$.

Shearn, M. A., and Tu, W. H. (1965). American Fournal of Medicine, $39,312$.

Shearn, M. A., and Tu, W. H. (1968). Annals of the Rheumatic Diseases, 27, 27.

Smith, P. M., Middleton, J. E., and Williams, R. (1967). Postgraduate Medical fournal, 43, 439.

Talal, N., Zisman, E., and Schur, P. H. (1968). Arthritis and Rheumatism, 11, 774 .

Wilson, I. D., Williams, R. C., and Tobian, L. (1967). American four nal of Medicine, 43, 356

Wrong, O. (1965). fournal of Clinical Pathology, 18, 520.

Wrong, O., and Davies, H. F. (1959). Quarterly fournal of Medicine, 28 259.

Zisman, E., Buccino, R. A. Gorden, P., and Bartter, F. C. (1968). Archives of Internal Medicine, 121, 118.

\section{British Medical fournal, 1970, 3, 146-147}

Cummary: In an outbreak of respiratory syncytial (R.S.) virus infection in a maternity hospital the respiratory illness was of a mild nature and the virus was not found in infants without respiratory symptoms. This confirms the suggestion that R.S. virus can infect infants at a very early age. Rapid diagnosis was achieved by applying the direct fluorescent antibody technique to cells in nasal secretions. This proved to be more sensitive than culture techniques where there was delay between the onset of respiratory symptoms and submission of specimens to the laboratory.

\section{INTRODUCTION}

That newborn babies may sometimes suffer from a relatively mild respiratory illness due to respiratory syncytial (R.S.) virus was recently suggested as an essential part of a hypothetical explanation of the pathogenesis of bronchiolitis in infants (Gardner, McQuillin, and Court, 1970). Evidence to support this suggestion has been found during the investigation of an outbreak of respiratory infection among babies at the Princess Mary Maternity Hospital, Newcastle upon Tyne. This is the first report of an outbreak of R.S. virus in a maternity hospital in the neonatal period, and the mild nature of the clinical illness contrasts sharply with the devastating effects of introducing other viruses into maternity nurseriesfor example, parainfluenza I (Sendai) and Coxsackie B virus (Kuroya, Ishida, and Shiratori, 1953; Javett et al., 1956). R.S. virus has been isolated from infants with respiratory infections in a premature nursery (Berkovich and Taranko, 1964), though in this series their ages ranged from 1 to 6 months.

\section{Materials AND METHODS}

A fine plastic feeding tube (size 5 French), substituted for the much larger distal tube of a standard disposable mucus extractor, was passed through each nostril in turn, mouth suction being used to aspirate secretions from the nostrils and nasopharynx into it. The tube was then detached, placed in a universal container, and transported to the virus laboratory in melting ice. The material, usually consisting of saliva as well as blobs of mucus, was expelled from the tube into a bijou bottle. The blobs were broken up by gentle pipetting and the cellular content washed and centrifuged. The supernatant fluid was used for virus culture and the cellular deposit for fluorescent staining for R.S. virus. The culture techniques and the cell lines used have been previously described (Sturdy, McQuillin, and Gardner, 1969).

Immunofluorescent Staining of Material.-Slides were prepared, fixed, and stained for R.S. virus as described previously (McQuillin and Gardner, 1968; Gardner and McQuillin, 1968). The secretions from these newborn babies were less easy to examine directly than those from older patients, containing fewer cells, but they still proved useful for rapid diagnostic procedures.

\section{The OUTBREAK}

On 1 February a baby who was still in the special care nursery at the age of $7 \frac{1}{2}$ weeks because of low birth weight was clinically suspected of suffering from mild bronchiolitis; after two days of a snuffly nose with a clear discharge, he had developed a cough and a slight wheeze. The same diagnosis was independently suggested by a second observer next day, and on the following day his nasal secretions were examined and found to be positive for R.S. virus by the fluorescent antibody technique (later confirmed by culture). During the next six weeks a further 25 babies were investigated-nine of them on two occasions-either because of contact with infected babies or because of respiratory symptoms.

R.S. virus was found in eight babies altogether, of whom seven had at some time been in the special care nursery, and one had gone straight from the labour ward to a normal lying-in ward. All eight babies had respiratory symptoms, starting with a snuffly nose with a clear discharge, at ages between 10 and 52 days (in six cases between 10 and 15 days); all developed a cough between two and seven days later, and three also developed a mild expiratory wheeze. None of the babies was worryingly ill except for one with clinical and radiological pneumonia; Staphylococcus aureus was cultured from a cough swab and a persistent conjunctivitis. Two of the three babies who developed a wheeze also developed a cardiac murmur, possibly in the ductus arteriosus; this disappeared, however, as they recovered.

Of the remaining 18 babies not infected with R.S. virus, 14 were investigated because they had been in the same room as a positive case and four because they had developed a snuffly nose at the age of 1 to 5 days (one of these was found to be infected with a rhinovirus). 